SB 945
S7 H5

Copy 1 



\section{The Spruce Budworm}

\section{and Larch Sawfly}

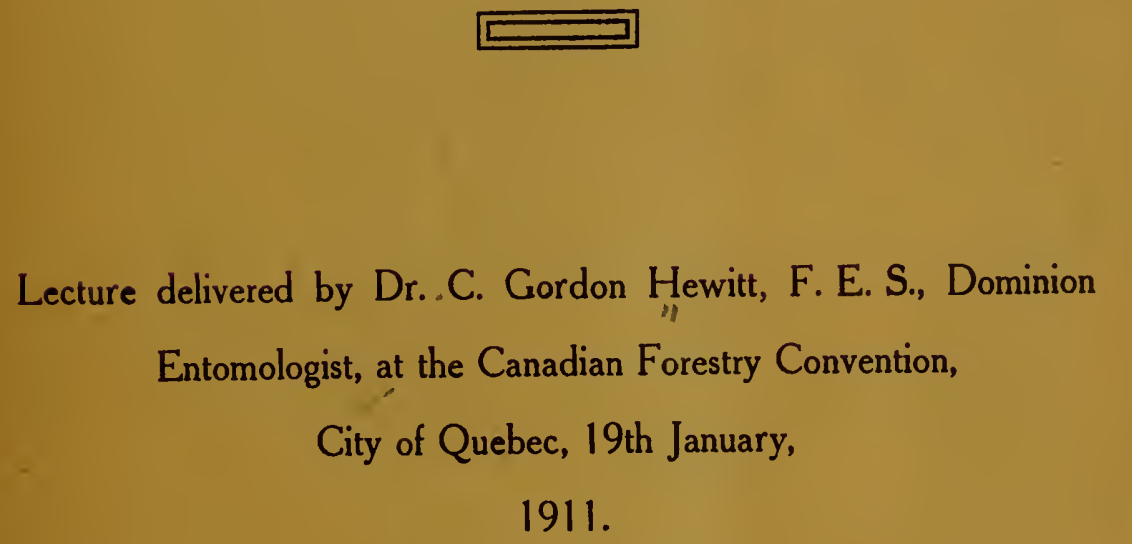

Reprint from the Roport.

The British Whig Publishing Co., Limited, Kingston, Ontario, 1911. 


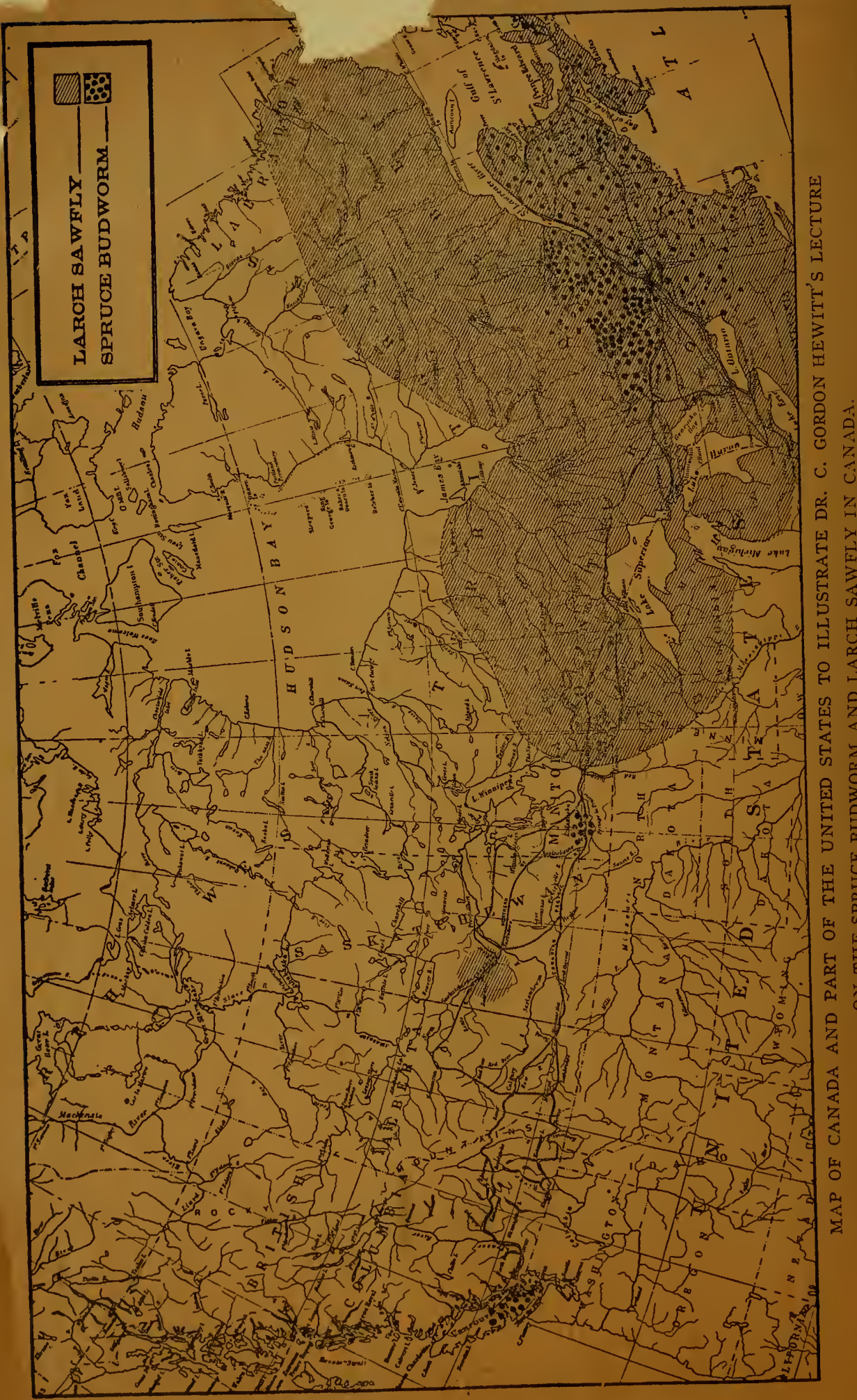




\section{THE SPRUCE BUDWORM ND LARCH SAWFLY \\ Dr. C. Gordon Hewitt, F.E.S., Dominion Entomologist, Ottawa.}

During this convention forest conservation has been fully discussed, but thi. discussion has been more or less limited to the consideration of one factor in forest destruction-fire. What has struck ine is the fact that except for two references, in almost as many words, there has been no mention of another great destructive agency, namely insects. This seems peculiar when you think of one insect which when it appeared first (1882-6) destroyed all the mature tamarack from Nova Scotia to Winnipeg. When we have such an insect spreading more destructively than any fire, because it is selective in its destruction, it is quite unintelligible to me why there should be this apparent neglect of this factor. You will observe that I say apparent neglect, because I do not think there is any real neglect on the part of those interested.

In this matter we cannot consider one factor to the exclusion of the other.s. The three factors chiefly responsible for the destruction of our forests-fire, insects and plant diseases, are all closely interrelated. Possibly the reason that insects are not generally mentioned is because, working as they do quietly and insidiously, they carry on their destruction unnoticed except by the expert who is trained to detect them; whereas a fire can be observed by the smallest child and its ravages cover a large area in a very short space of time.

I believe that in Canada we suffer quite as much in the aggregate from insects as from fire. It has been estimated by the United States Department of Agriculture that the annual loss in the forests of that country through destructive insects amounts to over $\$ 65,000,000$. This is figured from actual observations in the forests covering a period of at least ten years. You can thus realize the enormous loss caused by insects which we shall have to consider as affecting first, the growing timber; secondly, timber products; and thirdly, the second growth upon which the perpetuation of the forest depends.

Twelve months ago at the first meeting of the Commission of Conservation I called attention to the important relation that insects bear to forestry in Canada and to the conservation of our forests, and the urgent necessity of studying all the facts possible concerning insects bearing upon this relation. I am now addressing a body of men most of whom are concerned in the practical aspect of forestry, and to you I repeat with increased emphasis that as insects play so large a part in the destruction of forests, the increasing importance of our forests as sources of timber, for regulating the water supply, for preventing erosion and for the other objects with which you are all familiar, will make it increasingly essential that, by careful scientific investigation, we shall be in possession of these facts concerning the life-histories, habits and natural means of zontrol and other factors upon which alone any measures of control can be based and recommended.

It is not my intention to retrace my steps over the ground which was traversed in my previous address. I was requested to speak to you upon two insects which have had and are at present exercising a serious influence upon some of our important forest trees: the sawfly which is attacking the larch or tamarack, and the spruce budworm whose attacks upon the spruce and balsam in the province of Quebec have been the cause of much alarn on the part of those interested in the timber and pulpwood limits.

Both of these insects belong to a class which is destructive by reason of the larvae defoliating the trees, and this class of insects is not so serious in its results as the group of bark beetles, which are responsible for enormous damage to coniferous trees as the records of the investigations in the United States show Nevertheless, I shall be able to show you that under certain conditions defoliating insects may be the primary cause of most serious losscs. 
The results of the attachs of this insect, though a defoliating insect, are serious, though they are more complex than would appear at first signt. P.ckard stated that the destruction of the spruces along the Maine coast in the early 'eighties' was chiefly due to this insect. It is not unlikely, however that the budurin was fol lowed by other insects. The primary injury is to the buds which are dicstroye and thus the growth is checked-a serious matter on a slowly-growing tre The repeated defoliation weakens the vitality of the tree with the result that reaches a certain point at which it is susceptible to the attacks of bark-beetle the chief of which is the Eastern Spruce Beetle (Dendroctonus piceaperda Hop. This beetle is more serious in its effects than any other enemy of the spruce, a it kills the tree which is then readily attacked by timber borers and fungi. As Hopkins has stated this species of bark-beetles has caused the death of a very large percentage of the mature spruce over an area of thousands of miles in the spruce forests of New York and the New England States and southeastern Canada. It has been found killing the mature spruce in Quebec, New Brunswick and Nova Scotia. The greatest danger to my mind, therefore, of the present outbreak of the spruce budworm in Quebec is not so much the direct killing of the trees by repeated defoliation but the reducing of the vitality of the trees and rendering them more suspectible to the attacks of bark beetles especially the spruce beetle which is present in many of the affected localities, and one of my chief objects in making a tour of inspection of the most severely infested localities will be to discover whether the trees are being weakened in vitality, and this secondary attack of bark beetles is taking place. That the spruce budworm is able, however, to cause the death of the trees directly is demonstrated in British Columbia where it has killed a considerable quantity of the young Douglas firs of the second growth which is a most serious matter as affecting the natural regeneration and afforestation.

Spreading like fire by means of the moths it is impossiole to check tl e spread of this pest by ordinary means. Two things only appear to be possible; to study, in the manner I describe later in my account of the larch sawfly, the progress of the work of the parasites with a view to ascertaining whether the natural means of control are proving effectual and, by careful inspection of the infested areas, to cletect the beginning of the attacks of the bark-beetles upon the weakened trees. As soon as such attacks are observed the trees should be immediately dealt with, as is possible in the early stages of the outbreaks of these insects. By such timely action it may be possible to prevent the spread of the beetles and the weakened trees, instead of being killed by the latter, will have the opportunity $\omega$ recover, should the outbreak of the budworm be transient or checked by natural causes. These bark beetles are the most destructive of all insects attacking conifers but, at the same time, if the necessary steps are taken, it is possible to prevent serious outbreaks. The chief essential is that the forest rangers shall have such entomological knowledge as will enable them to detect the first signs of the outbreak the chief of which is the turning yellow or red of the tops of the trees. The presence of the spruce budworm will make such detectinn more difficult. If the identity of the species of beetle is scientifically determined, it is usually possible to recommend the measures to be taken to check tlie further spread of the insect.

A study of the parasites of the spruce budworm, both in Quebec and British Columbia, is being made with a view to ascertaining the extent of their work. This insect is stated not to have many parasites. So far, we have discovered about seven species of parasites which attack it, and next year we hope to have sufficient material to enable us to estimate the degree of parasitisation.

\section{The Larch Sawfly.}

This 'larch-worm,' as it is sometimes called, since the defoliation of the larch or tamarack is caused by the caterpillar, has been known in Europe since the early part of the nineteenth century where it was injurious to the European larch in cer- 
tain regions of Germany. It was first discovered in America by Dr. Hagen of Harvard University who recorded it in the 'Canadian Entomologist' in 1881 . In that and the two following years it was found through the New England States where great destruition of the larch was caused. It was not long in reaching Canada, for 188. Ur. Fyles reported its appearance in Quebec on Larix Americana. Two zars later, my predecessor, Dr. Fletcher, gave an account of its occurrence in his inual report as Dominion Entomologist: it occurred throughout the east in the rovinces of Ontario, Quebec, New Brunswick and Nova Scotia. In 1905 it in assumed serious proportions and it will be of interest to quote Dr. Fletcher's eference to it in his report of that year. After mentioning the fact that it reached Canada in 1882, he states that after three or four years of being stripped, the larches over millions of acres, and practically over the whole of Eastern Canada, were wiped out. With this large destruction of its food plant, the insect practically disappeared until 1904 when it again become noticeable upon ornamental European larches and on larches in swamps. Further, he says: 'A feature of the last outbreak of 1882 to 1885 was the rapidity with which the attack spread, and the suddenness with which it disappeared. Occasionally specimens of the sawfly or of the colonies of larvae have been secll from time to time since 1885 , but there has been no noticeable destruction until the present year.' This last attack has now spread along the forest belt into Manitoba where I have observed it during the past two years, and it has also been reported from near James' Bay and recently as far west as Battleford, Saskatchewan. I have not found it attacking the western larch in British Columbia, but its occurrence there would not be surprising. East of Winnipeg it may be said to extend to the Atlantic as I have found it throughout to the eastern region of Nova Scotia. Its present known distribution in Canada, therefore, is over an area of 2,500 miles in extent. In the United States it extends from the Atlantic coast to Minnesota and as far south as Pennsylvania.

The results of the first outbreak were disastrous as was seen from the report just quoted. The second growth of larch is now being attacked, and we cannot prophesy as to the result of this renewed outbreak. Even should these trees escape, I shall show later in what manner the timber has been reduced in value and utility in most cases by the effect of the first visitation of 1882-5 upon the young second growth.

The habits and life-history of the insect are such as to render it iniurious in both the caterpillar or worm stage and the fly stage. The winter is passed by the larva in a cocoon under the turf round the base of the tree. In May the larvae transform into the perfect insect and the flies begin to emerge during that month. An interesting feature of the productive powers of the larch sawfly is that it can reproduce parthenogenetically, this means that the females can deposit eggs which, although they have not been fertilized by the males, are not infertile but produce larvae of the sawfly. This interesting phenomenon which also occurs in certain other insects, is of importance as the productive power of the species is increased when the necessity of the female meeting a nale is dispensed witin. Shortly after emerging the females begin to deposit their eggs. The eggs are always deposited in the terminal green shoots of the larch and never on any other part of the tree. In laying the eggs the female sawfly makes an incision in the tender stem of the shoot by means of a pair of saw-like instruments at the end of the body and into this incision the egg is pushed. The egzs are usually posited in a double row in the shoot and as many as forty or fifty eggs may be found on a single green shoot. As they are usually cleposited along one side of the shoot the injuries inflicted by the saw-like appendages of the female cause the shoot as it grows to curl. In many cases the injuries are so severe as to kill the shoot and the presence of the dead and reddish-brown shoots often serves as an indication of the presence of the insect. In about a week to ten days after deposition the eggs hatch and the young pale green caterpillars emerge and immediately begin to feed upon the green verticels of leaves. As they become alder they feed in masses, sometimes as many as fifty or sixty caterpillars in a single 
cluster and, feeding in this manner, they mpletely strip the branches of ail green leaves which gives the trees a winter a bect in the middle of summer. The caterpillars are full-grown in three to four yeeks aud, during their 1 ves, the cast their skins five times. As the period during which the sawflies em rge from the cocoons is a lengthy one, there is a correspondingly long period auring which the eggs are deposited and the larvae emerge; in consequence o: this, one may find recently-emerged caterpillars feeding side by side with tull-grorin specimens and the caterpillars may be found in Canada feedi ' $x$ as late as the second week in August. As the first newly hatched caterpillars wcre foind during the last week in May in the neighbourhood of Ottawa and full-grnwn caterpillars in August, and as the caterpillar stage is not a long one, it might be assumed by anyone who had not made these observations that there were two broorls of the sawfiies during the year, which has been proved not to be the case.

The full-grown caterpillar measures about two-thirds of an inch in length. Its color is bluish or glaucous green, the lower surface being a lighter green. The head and three pairs of thoracic legs are jet black. It also possesses seven pairs of abdominal legs. When the caterpillars are full-grown they either craw" down or drop from the tree and penetrate the turf round the base of the tree to the depth of a few inches. There they spin a brown oval cocoon about twofifths of an inch in length, and in this the winter is passed, the caterpillar trancforming into the perfect insect in the following year as previouslv describcd. The sawflies are black with the middle portion of the hind-body or abdomen a bright resin-red and they measure about half an inch in length.

The forester is naturally most concerned in the measules which may be adopted to control or prevent the attacks and spreading of a pest. Means of control are of two kinds, those of nature and those of man; the latter are frequently adaptions of the former. In cases where a pest has gained some headway and extends over a large area, especially of virgin forcst. it is normally impracticable tn adnpt any measures of control which will be of value. We are comnelled to wait the disappearance of the pest either by the exhaustion of its food supply by the killing of the trees or bv its extermination lhrougl the attacks of narasites or other natural enemies. For this reason the study of the uatural means of control is attaining considerable importance in entomological problems and mention will be briefly made of such a sturly which I have been making during the last few years in connection with the outbreak of this insect in England and in Canada. In that investigation it was found that the commonest parasite attacking the caterpillars of the sawfly in England was an Ichneumon Mesoleius aulicus and it was decided to study the progress of the work of this parasite from year to year. In 1908 it was found that it had attacked and destroyed 6\% of the caterpillars of the previous year. Next year the percentage of caterpillars killed by the parasites was $15 \%$ and last year the percentage of caterpillars killed by this natural means of control was nearly $65 \%$, an enormous increase which means that the parasite has practically gained control over the sawfly, and this is borne out by the observations made by Mr. Mangan who is continuing the work, who informs me that during the past summer the trees, instead of having the completely burned appearance and defoliated condition of the previous vears, had the normal green appearance, so it was not a little difficult to discover the insects. This disappearance was almost entirely due to the natural causes, the chief of which was the parasite Mesoleius aulicus. The chief of the other potent natural causes were the small voles or field mice and the birds, especiallv the tits. A system of bird encouragement and protection was initiated when it was discovered that certain species of birds were feeding upon the caterpillars, especially as there was a relative scarcity of birds in the infested region. Nest boxes were distributed, an additional number being provided each year. Last vear there were nearly 300 boxes and over $50 \%$ of these were occupied, which indicates a considerable increase in the number of birds in view of the scarcity previous to their encouragement. Such a system of bird protection, in other 
words the encouragement of the na: on in Europe not only by individuals are important natural resources.

This study of the parasitic an other means of natural control is the only line of investigation which can be arried on and its practical results, although they may not be apparent at first sight, are nevertheless of importance as we can measure the efficacy and progress of natural causes of control, and in this way alone can/prophesy the course that the outbreak will take, which will enable the forester to act accordingly. During the last year a beginning was made of a stucly bf the parasites of this sawfly in Canada, the chief of which was found to be a small insect Coelopisthia nematicida Packard, which deposits its eggs inside the cocoon by piercing the cocoon with its elongate ovipositor. The eggs are deposited on the hibernating caterpillar lying inside the cocoon and on hatching the parasitic larvae feed upon it and so destroy it. From the prevalence of this parasite which has been reared from cocoons found not only near Ottawa but also from Massachusetts, I am inclined to consider it an important factor in the natural control of the pest.

The serious result of the attack of this insect does not consist in the destruction of the mature timber alone, but also in its effect upon the young second growth. I have previously shown how the injury to the young growing shoot by the female in inserting her eggs may either kill the shoot or cause its curvature and it may be so strong as to cause the shoot to curve through a complete circle. Usually, however, a strong curve in the stem is formed and an erect position is gained subsequently. This strong curve or kink on the stem has a serious effect on the growth of the timber, and as a result of these injuries you may see the young larches from Cape Breton, Nova Scotia, almost to Winnipeg having the main stem curved in various ways, as my illustration shows, rendering the future timber totally insuitable for the best uses to which the larch is put. The results of this insect's work, then, are twofold, the killing of the mature trees by repeated defoliation and the permanent injury to the young second growth which enormously reduces the value of the subsequent timber and in this manner not only is the larva injurious but the mature insect also. As in the case of the spruce, the trees weakened in vitality by defoliation by the caterpillars will be especially subject to the attacks of the bark-boring beetles and also of those fungi to which the larch' is susceptible.

The ChArrman-I am sure that as Canadians we will all congratulate ourselves that we have a Minister of Agriculture who has the good sense to profit hy the scientific assistance of such men as Dr. Hewitt. I am also sure that every one of us feels regret that our good friend, Senator Edwards, was not here to appreciate what science can do in a practical way for the development of the forestry industry. Personally $I$ do not know when $I$ have enjoyed a lecture as much as I have enjoyed Dr. Hewitt's address. I trust' we shall have an opportunity of hearing him again at another meeting of our Association, for I feel that such addresses as his cannot but be of benefit to us individually and as an organization.

It being 10 p.m. the convention adjourned. 

